\title{
AUGMENTED REALITY FOR CULTURAL HERITAGE: THE REBIRTH OF A HISTORICAL SQUARE.
}

\author{
A. Scianna ${ }^{a}$, G. F. Gaglio ${ }^{b}$, M. La Guardia ${ }^{b}$ \\ a ICAR-CNR (High Performance Computing and Networking Institute - National Research Council of Italy) at GISLab c/o D'Arch, \\ Polytechnic School of University of Palermo, Viale delle Scienze, Edificio 8, 90128 Palermo, Italy \\ andrea.scianna@cnr.it \\ b ICAR-CNR (High Performance Computing and Networking Institute - National Research Council of Italy), at GISLab, \\ Via Ugo La Malfa 153, Edificio 8, 90146 Palermo, Italy \\ gfulvio.gaglio@gmail.com ; marcellolaguardia87@libero.it
}

\section{Commission II}

KEY WORDS: Cultural Heritage; Augmented reality, Virtual Heritage, 3D printing, Photogrammetry, TLS.

\begin{abstract}
:
The case study, faced in this paper, arises in the context of Interreg Italia-Malta European project named I-Access, dedicated to the improvement of accessibility to Cultural Heritage $(\mathrm{CH})$. Accessibility considered not only as the demolition of physical architectural barriers, but also as the possibility of fruition of $\mathrm{CH}$ through technological tools that can increase its perception and knowledge. Last achievements in photogrammetry and terrestrial laser scanner (TLS) technology offered new methods of data acquisition in the field of $\mathrm{CH}$, giving the possibility of monitoring and processing big data, in the form of point clouds. Ever in this field, reverse engineering techniques and computer graphics are even more used for involving visitors to discover $\mathrm{CH}$, with navigation into 3D reconstructions, empowering the real visualization adding further 3D information through the Augmented Reality (AR). At the same time, recent advances on rapid prototyping technologies grant the automated 3D printing of scaled 3D model reconstructions of real $\mathrm{CH}$ elements allowing the tactile fruition of visitors that suffer from visual defects and the connection with 3D AR visualizations. The presented work shows how these technologies could revive an historical square, the Piazza Garraffo in Palermo (Italy), with the virtual insertion of its baroque fountain, originally placed there. The final products of this work are an indoor and an outdoor AR mobile application, that allow the visualization of the historical original asset of the square. This study case shows how the mixing of AR and the rapid prototyping technologies could be useful for the improvement of the fruition of $\mathrm{CH}$. This work could be considered a multidisciplinary experimentation, where different technologies, today still in development, contribute to the same goal aimed at improving the accessibility of the monument for enhancing the fruition of $\mathrm{CH}$.
\end{abstract}

\section{INTRODUCTION}

For many years, the world of $\mathrm{CH}$ has benefited from the possibilities offered by digital technology. The digitisation of $\mathrm{CH}$ is fundamental not only for the dissemination of its knowledge but also for its enhancement. Paintings, sculptures and monuments can indeed today be seen in a completely new way through the use of modern devices. A degraded or disappeared work can thus return to live through what is called Cultural Computing.

At the same time recent advances in survey operations allowed to make accurate reconstructions of monuments and archaeological sites also in impervious areas. In particular, in the field of photogrammetry, the Structure from Motion (SfM) algorithms allows to obtain dense point clouds on the basis of chunks of photos taken around the surveyed area. This technology, with the help of a network of ground control points (GCP) taken with a GNSS survey, achieve to obtain a 3D restitution of the environment with centimetric accuracy.

Ever in the field of survey operation, the laser scanner technology nowadays offers different solutions (close range, medium range and long range) that allow to obtain $3 \mathrm{D}$ dense point clouds of outdoor and indoor environments with millimetric accuracy.

The recent evolution of Unmanned Aerial Vehicles (UAV) offered new solutions for survey operations thanks to the possibility of on the flight acquisition of nadir and oblique images, opening new scenarios for monitoring and reconstruction aims (Dominici et al., 2017; Lingua et al., 2017; Mangiameli and Mussumeci, 2017; Masiero et al., 2017; Pepe and Fregolese, 2019; Piras et al., 2017; Remondino et al., 2011; Vacca et al., 2017) .
The acquisition and management of $3 \mathrm{D}$ data on the $\mathrm{CH}$ have become, over the years, more and more accessible, up to allowing, nowadays, an ever more immersive use of artistic, historical and architectural content, thanks to Virtual Reality (VR) enhancement and, in particular, to Augmented Reality (AR). Modern surveying techniques also allow rapid data acquisition to obtain highly detailed 3D models useful for different 3D digital documentation applications (Balletti et al., 2014; Ioannides et al., 2016, Scianna and La Guardia, 2018).

The spread of mobile devices such as smartphones and tablets, even at low costs, has allowed most users even easier access to applications that previously required only dedicated equipment. The AR is making its way reasonably quickly in many fields and it is no longer to be considered just a playful or entertainment medium, but a tool to be used to observe and study reality, also in the field of CH (D'Agnano et al., 2015).

For this reason, it represents a strong ally in scientific and cultural applications, and this is why it has been chosen for the experimentation described in this paper. The experimentation aims to allow the fruition of a monument by showing its history through the virtual relocation in its place of origin.

In the following sections of this article, after an essay on the state of the art on the use of AR as a tool for valorization and fruition of $\mathrm{CH}$, the case study will be described. This concerns the virtual reconstruction of the Garraffo baroque fountain and Piazza Garraffo, a square in the historical district of Vucciria, sited in Palermo (Italy) starting from images obtained from a photogrammetric reconstruction based also on a GNSS survey. The implementation of an indoor and an outdoor application, that foresees the virtual repositioning of the fountain in its original location in Piazza Garraffo, will be shown. 
The indoor application concerns the 3D printed model of the fountain to be used as a target for the indoor AR visualization inside Piazza Garraffo square.

The outdoor application consists on the AR visualization of the fountain walking on the real outdoor environment of Piazza Garraffo.

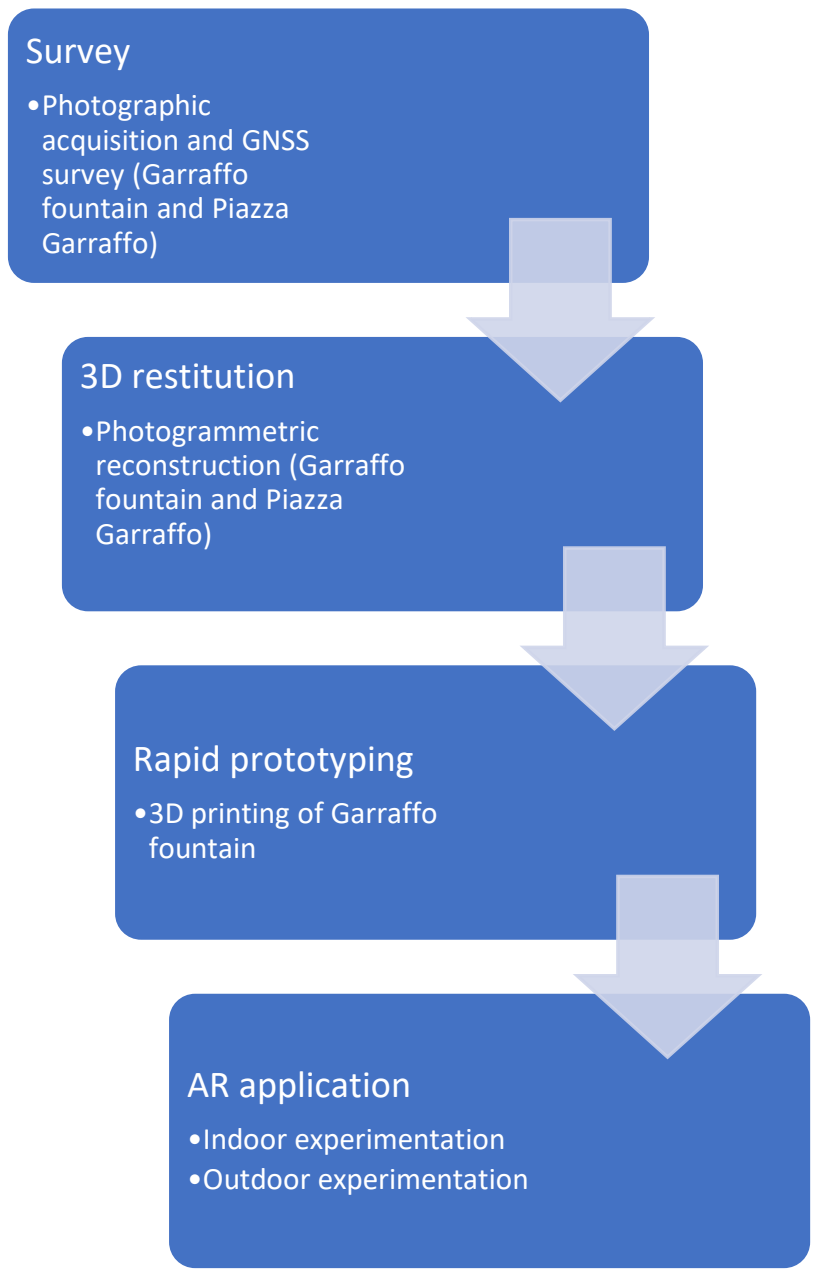

Figure 1. The Workflow

\section{$2 . \quad$ CULTURAL HERITAGE TOLD THROUGH AUGMENTED REALITY}

$\mathrm{CH}$ mainly benefits from the application of Augmented Reality. This immersive technology allows users (scholars, researchers, etc.) to explore cultural and artistic elements more engagingly. The usefulness of AR is, in fact, the possibility to improve the visitor's experience, to virtually reconstruct the $\mathrm{CH}$ and to explore it (Bekele et al., 2018). AR in the cultural sphere can also achieve educational functions if used as a support tool for educational activities such as in the case of the MAUS Museum, where the 3D reconstruction of extinct living beings linked to their remains allows obtaining a decidedly more stimulating and engaging perception of what is observed, unlike the classic reconstruction of a physical model (Invitto et al., 2014). Although we can already talk about AR only considering the use of audio guides and interactive monitors, as they enrich the visitor's experience by adding information to the surrounding environment, it is since 2001 that is possible to find the first examples of AR in the sense in which it is understood today. A modern AR system provides a combination of the real and the virtual world where the user can interact with them in real time (Liarokapis, 2007). Reality is augmented through elements that are added or replaced to real ones through listening through earphones or observation via PCs, smartphones, tablets, etc. In particular, with the wide-spread use of electronic devices, today, it is possible to talk about Mobile Augmented Reality (MAR) (Galatis et al., 2016). In terms of use and enhancement of $\mathrm{CH}$, ARCHEOGUIDE can then be considered the first example of what it is possible to obtain through the use of devices that allow to observe reality by superimposing on the real site tridimensional elements generated by the computer. The AR interface, always in contact with the surrounding environment, accompanies the visitor along a guided tour taking advantage of audio guides and 3D reconstructions of ruins belonging to $\mathrm{CH}$ (Vlahakis, et al., 2002). The possibility of showing remote or no longer existing places in a new way that stimulates interest has begun to involve more and more museums around the world. Large panels with images that can be observed through particular devices, such as the UMPCs, have allowed a connection between the elements displayed in the museums and the archaeological sites in which they were found (Zöllner et al., 2009). In some cases, the AR has shown itself through the use of cultural tours guided by virtual characters inspired by past personalities (Kim et al., 2009). The aim of the AR is, therefore, to improve and sometimes to simplify the knowledge that the user can obtain not only through virtual information but, in general, through an indirect vision of the real world. Unlike the virtual reality, which completely immerses the user in a fictitious world, the AR technology increases the senses of the individual (Carmigniani, et al., 2011). The ARtSENSE project, for example, uses a customised AR guide for each visitor combining input from visitors' biological signals, their movements and the sounds in the environment (Damala, et al., 2012). Today, AR is not a simple tool of entertainment, but a useful method also for the dissemination of knowledge and to facilitate access to places that are not easily accessible. Moreover, thanks to the use of 3D virtual models that allow reconstructions of elements belonging to past times, it is possible to have a newer and more complete view of objects of the past, today no longer in good state of preservation, and without the need to visit the real site (Marques, et al., 2017).

An essential component of AR applications is the tracking of user location. This can be camera-based as in the case of the ARCO project (Wojciechowski et al., 2004), or based on infrared or sensors, as in the case of the acoustic sensors of the installation of the Empty Museum (Hernández, et al., 2007).

Another fundamental aspect of AR is that virtual elements should be superimposed on the real world, taking into account the point of view of the observer, thus respecting the perspective rules. The kind of device used to obtain the simulation is, therefore, also important. The display is undoubtedly the essential part, present in all the dedicated devices, as it allows the representation of the virtual element and, generally, the interaction with it. There are different types: Head Mounted Display (HMD), Spatial AR (SAR) and Hand-Held Devices (HHD) are certainly among the most common. Smartphones and tablets are equipped with displays, but they also contain processors and memory units that also allow the execution of the software necessary for the realisation of the $\mathrm{AR}$, in order to send inputs through the touchscreen, the microphone or the position sensors.

The simply and widespread use of these devices is driving most of the research work in this area. Furthermore, most of the AR application development software on the market expects integration with smartphones. Vuforia, ARToolkit and DroidAR are just some of them. In particular, Vuforia allows the acquisition of $3 \mathrm{D}$ objects to be used as targets within the application to interact with the virtual component. In this way real objects belonging to artistic collections, parts of monuments or $3 \mathrm{D}$ prints can be used as a base for the realisation of 
applications that combine the virtual aspect with the tactile one, increasing the involvement of the user. It is from this idea that experimentation is born, which will be discussed in the next paragraph.

\section{THE GARRAFFO FOUNTAIN REVIVES IN ITS ORIGINAL SQUARE.}

The case study presented in this article concerns the realisation of an AR application through which it is possible to admire the virtual repositioning of the Garraffo fountain in Palermo in its original location. The fountain is located today in Piazza Marina in Palermo, the place where it was moved in 1862 . Sculpted by Gioacchino Vitagliano based on the design by Paolo Amato in 1698 , the fountain originally stood in Piazza Garraffo, opposite the Genius of Garraffo, at the centre of the Vucciria market in Palermo.

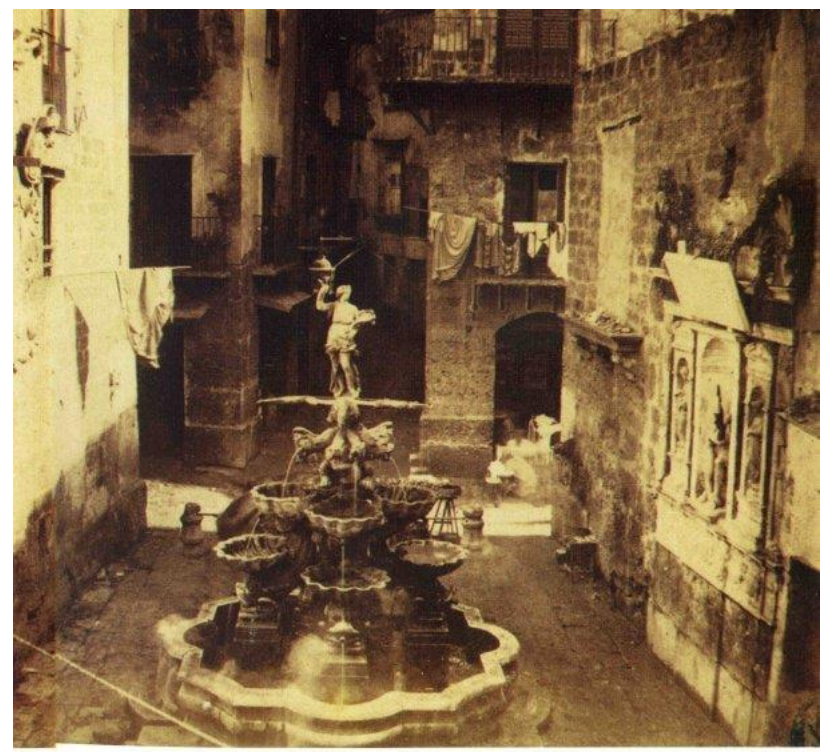

Figure 2. The Garraffo fountain in its original placement in Piazza Garraffo before the year 1862.

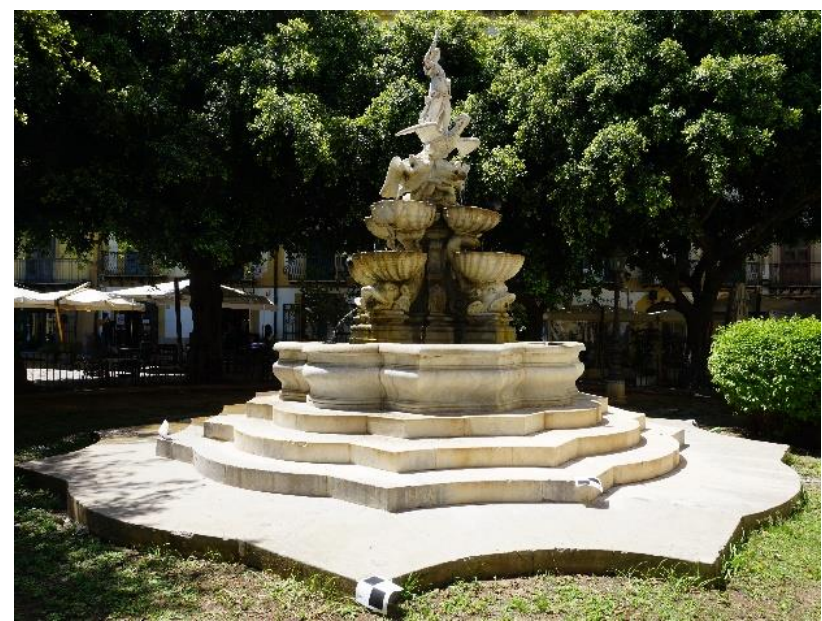

Figure 3. The Garraffo fountain nowadays, located in Piazza Marina.

From the large basin of a diameter of about 5 meters rises a pyramidal structure composed of dolphins that support, with the head and the tail, some shell-shaped basins. Above them are shapes of a hydra and an eagle fighting under the gaze of the goddess of abundance. The play of water starts right from the mouths of the hydra, fills the shell-shaped basins and pours into the large final basin. The whole structure rested on only one step. Instead, in its current location, two steps have been added, which follow the shape of the first, and a final marble platform.

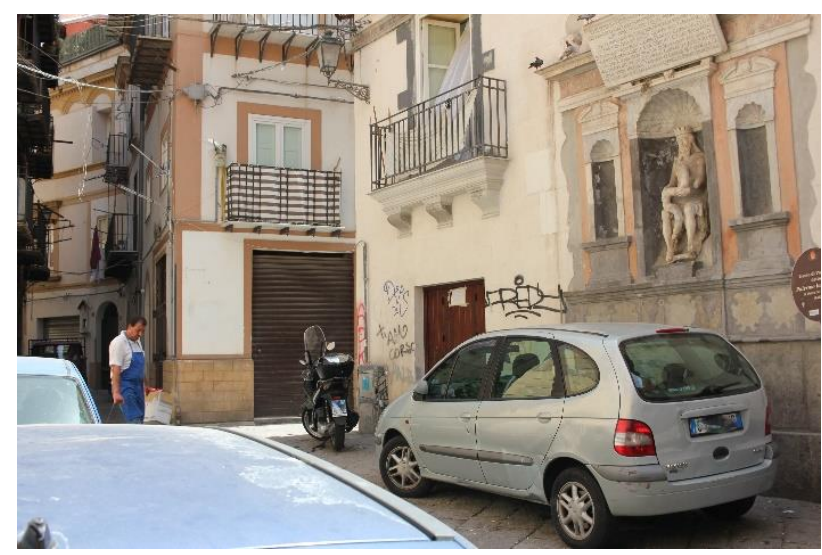

Figure 4. Piazza Garraffo, the square nowadays.

\subsection{The survey operations and the construction of $3 \mathrm{D}$ models.}

The augmented reality environments have been created through a photogrammetric reconstruction based on a GNSS survey. The surveyed areas have been two: the Garraffo fountain, located in Piazza marina, and Piazza Garraffo, located in the Vucciria district. The survey of the Garraffo fountain have been obtained using two chunks of photos, 90 photos taken from a Canon EOS 550D SLR Camera with $18 \mathrm{Mpx}$, and 123 photos taken from a SONY ILCE-6000 SLR Camera with $24 \mathrm{Mpx}$. For this operation a telescopic rod has been used to cover detailly all the sides of the fountain. The square of Piazza Garraffo has been obtained from a chunk of 411 photos taken from a Canon EOS 550D SLR Camera with $18 \mathrm{Mpx}$. On this phase a network of 2D static targets present inside the square has been selected, necessary for the matching of the AR on the outdoor experimentation.

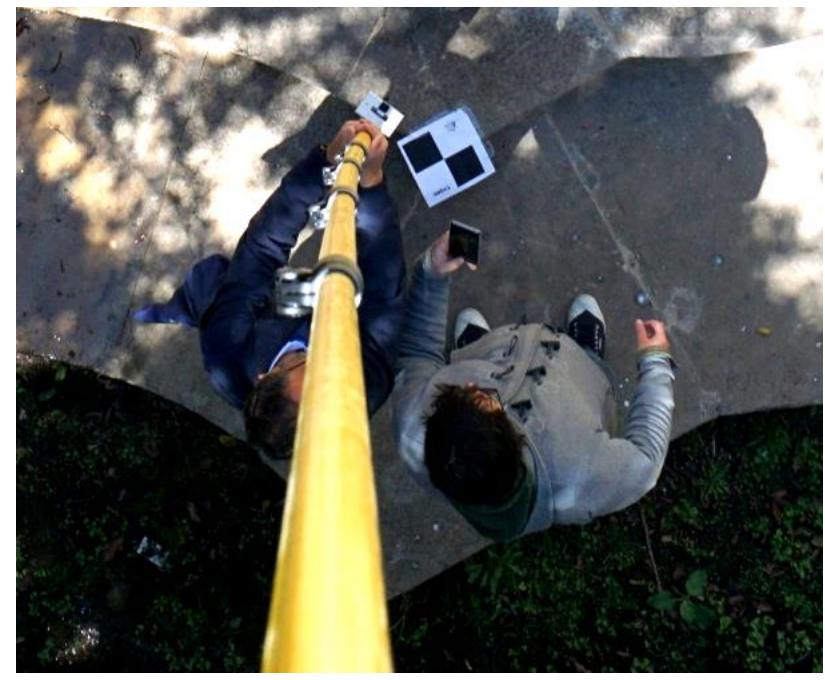

Figure 5. The telescopic rod used for survey operations.

\begin{tabular}{|c|c|c|c|}
\hline & N. Photos & $\begin{array}{c}\text { N. Ground } \\
\text { Control Points }\end{array}$ & $\begin{array}{c}\text { Error } \\
(\mathrm{m})\end{array}$ \\
\hline $\begin{array}{c}\text { Garraffo } \\
\text { fountain }\end{array}$ & 213 & 7 & $0.13 \mathrm{~m}$ \\
\hline $\begin{array}{c}\text { Piazza } \\
\text { Garraffo }\end{array}$ & 411 & 9 & $0.08 \mathrm{~m}$ \\
\hline
\end{tabular}

Table 1. Survey data. 
Survey operations allowed to make a photogrammetric reconstruction of both the environments using Agisoft Photoscan software obtaining an accuracy in the order of some centimeters. The level of accuracy obtained from survey operations is totally compliant with the development of an AR application. Once finalized the photogrammetric reconstruction, the dense point clouds generated allowed the creation of the 3D textured meshes, necessary for the construction of the AR environment.

Once obtained the 3D meshes of the Garraffo fountain and Piazza Garraffo, the models have been opportunely simplified in order to be inserted into the AR application. Indeed, the original huge number of polygons of both the models was not compliant with the creation of a smart application, because the final dimension of the app strongly depends on the weight of the models to visualize inside it. At the same time the AR visualization should be realistic, and the risk of a deep simplification is a strong loss of quality. For this reason, the solution is to find the true balance between the necessary level of detail (LoD) to maintain and the final weight of the 3D model. The procedure followed for the construction of the AR virtual models has been the simplification of geometry, maintaining, at the same time, a good texture resolution.

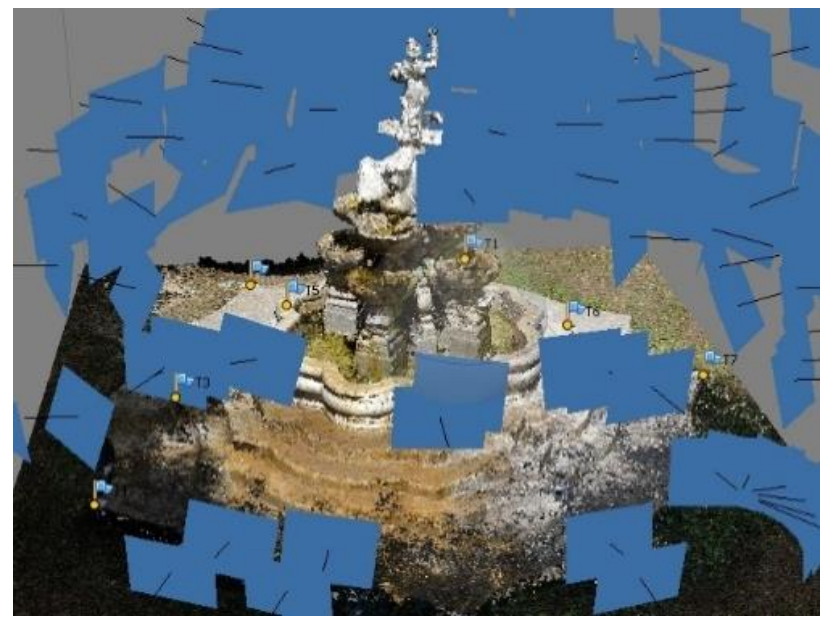

Figure 6. The photogrammetric reconstruction of the Garraffo fountain.

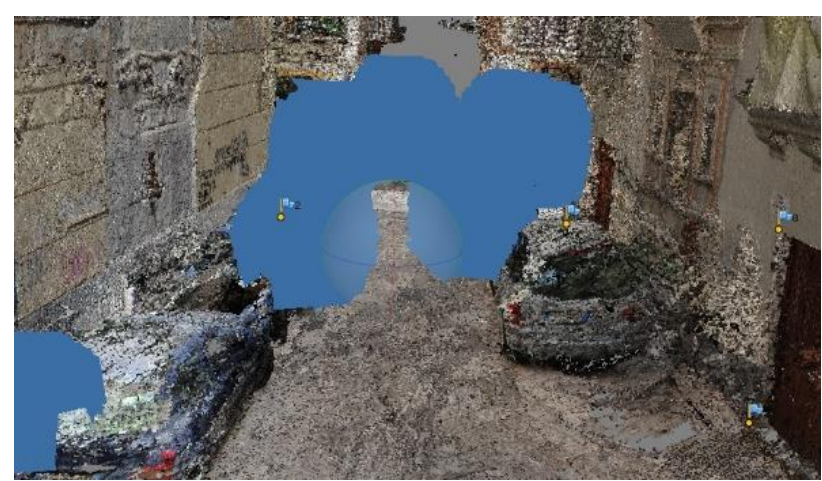

Figure 7. The photogrammetric reconstruction of Piazza Garraffo.

\subsection{The creation of the 3D printed model of the Garraffo fountain and the construction of the AR applications.}

As previously written, the 3D models generated from the photogrammetric reconstruction have been simplified for being inserted into the AR application. Different operations have been chosen for the $3 \mathrm{D}$ printing. In fact, differently from the $\mathrm{AR}$ requirements, a good LoD of 3D model geometry represents a fundamental feature for a correct rapid prototyping process.

For this reason, the 3D model of the fountain obtained from the photogrammetric reconstruction has been used for the generation of the 3D printing model.

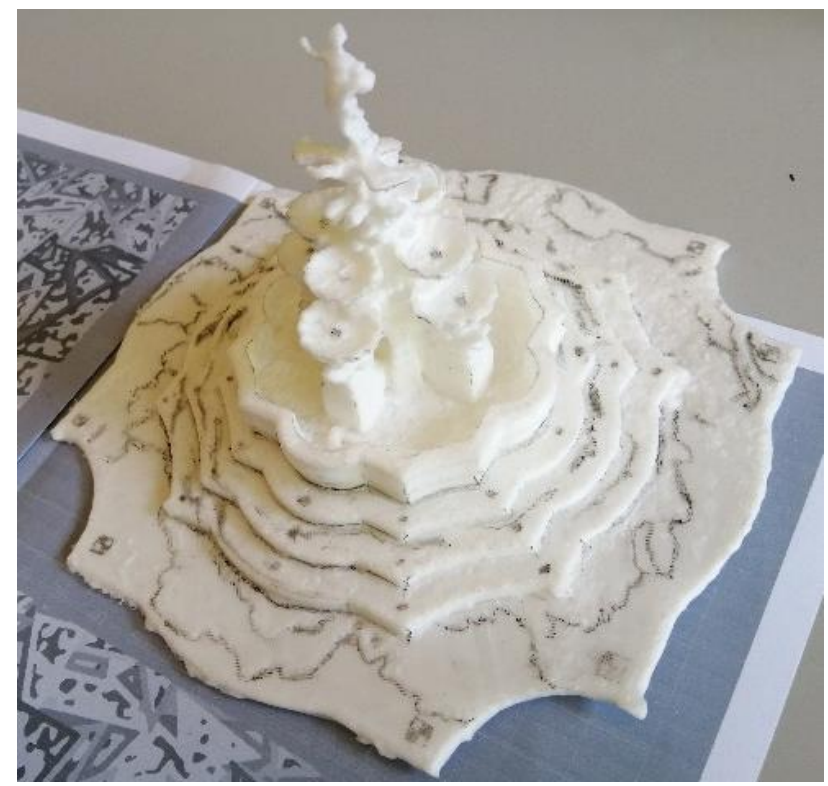

Figure 8 . The 3D printed model of the Garraffo fountain with the targets drawn on the surface.

The model surfaces have been controlled and corrected using Cloud Compare and Multimaker Cura software, and have been opportunely scaled in order to be sent to the $3 \mathrm{D}$ printer. The $3 \mathrm{D}$ model has been printed using a CREALITY CR10 SPro 3D printer in polilactic acid (PLA) material.

Once obtained the 3D printed model of the fountain, it has been used as a 3D target for the matching of the AR application. The software Vuforia has been used for this operation. The $3 \mathrm{D}$ printed model has been filmed from a smartphone camera from every angle of view, in order to create the target points necessary for the matching of the AR environment. During these operations some difficulties occurred for the 3D target recognition. This problem was due to the strong presence of curved surfaces of the $3 \mathrm{D}$ model of the fountain, that enabled the recognition of control point detection. This unexpected difficulty has been solved adding multiple targets, drawing on the surface of the 3D printed model.

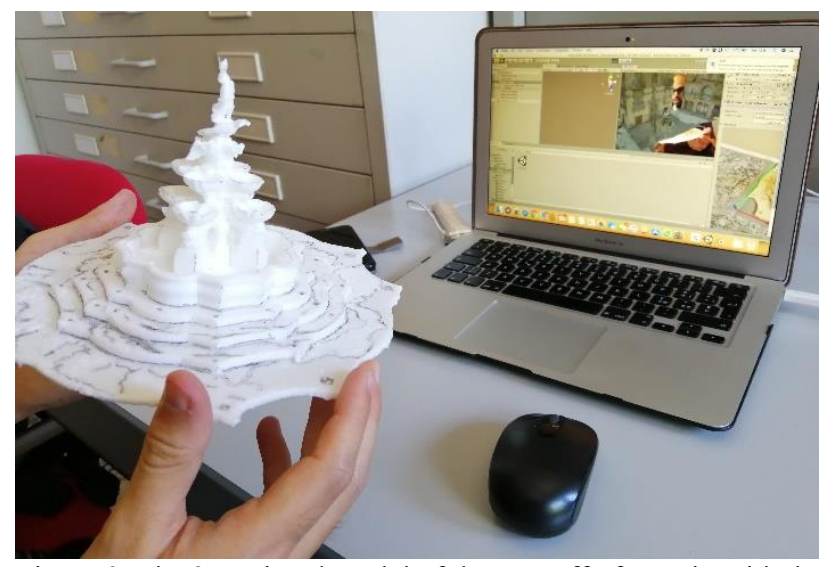

Figure 9. The 3D printed model of the Garraffo fountain with the targets drawn on the surface. 
The AR environment has been developed using Unity software with Vuforia extension, importing the 3D virtual model of the fountain, the 3D virtual model of Piazza Garraffo, the network of $2 \mathrm{D}$ targets and the $3 \mathrm{D}$ target of the $3 \mathrm{D}$ printed model of the fountain. The two experimentations of AR have been exported from this project, visualizing opportunely different elements and considering different targets. In particular, for the outdoor $\mathrm{AR}$ visualization has been matched the network of $2 \mathrm{D}$ targets with the $3 \mathrm{D}$ virtual model of the fountain. Instead, the indoor $\mathrm{AR}$ visualization has been created matching the $3 \mathrm{D}$ target of the $3 \mathrm{D}$ printed model of the fountain with the virtual models of the fountain and Piazza Garraffo.

\begin{tabular}{lll}
\hline $\begin{array}{l}\text { Augmented } \\
\text { Reality } \\
\text { application }\end{array}$ & $\begin{array}{l}\text { Indoor } \\
\text { Visualization }\end{array}$ & $\begin{array}{l}\text { TARGET:3D printed model of } \\
\text { the Garraffo fountain }\end{array}$ \\
\cline { 2 - 3 } & $\begin{array}{l}\text { OIRTUAL MODELS: 3D models } \\
\text { of the Garraffo fountain and } \\
\text { Piazza Garraffo }\end{array}$ \\
\cline { 2 - 3 } & Vutdoor & $\begin{array}{l}\text { TARGET:netwok of 2D static } \\
\text { targets inside Piazza Garraffo }\end{array}$ \\
\cline { 2 - 3 } & & $\begin{array}{l}\text { VIRTUAL MODELS: 3D model } \\
\text { of the Garraffo fountain }\end{array}$ \\
\hline
\end{tabular}

Figure 10. Schema of the 2 developed experimentations.

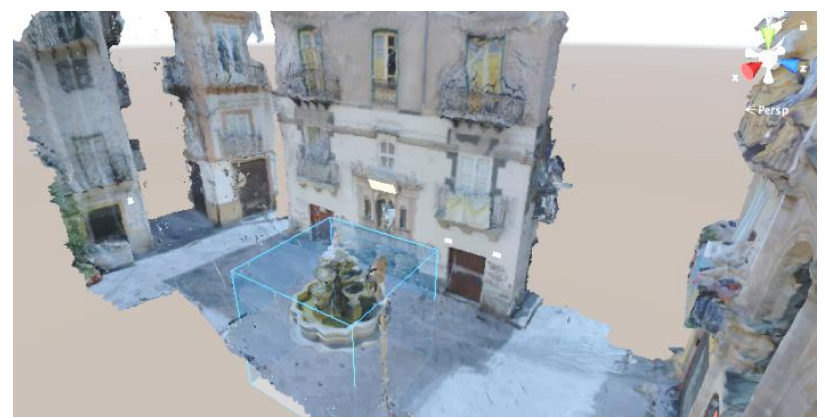

Figure 11. The construction of virtual environment for the AR application.

\section{4.}

\section{RESULTS AND CONCLUSIONS}

These two AR experimentations shows how an application that join the recent advances in 3D modelling, 3D printing, survey, and photogrammetry could be useful for providing an added value to the valorization of $\mathrm{CH}$. The indoor and outdoor experimented visualizations allow different ways of $\mathrm{CH}$ fruition, giving the possibility to visit an historical place in a past configuration no longer available in the real world.

Advancement in photogrammetric and 3D modelling technology are very helpful for the obtaining of complete and accurate 3D models. Also, development platforms such as Unity and Vuforia allow the creation of interactive $3 \mathrm{D}$ environments in a so simple way, in some cases without the need to program with code. As said before, some issues have been encountered during the acquisition of the 2D and 3D targets. Surface and shape of the target are very important in order to obtain a good recognition. In particular, in the outdoor application, it's been necessary to choose the 2D targets with particular attention. Signals and writings are easily recognizable, but the lighting conditions must be also taken into account. Moreover, using elements already present in site avoids attacking additional targets in the environment.

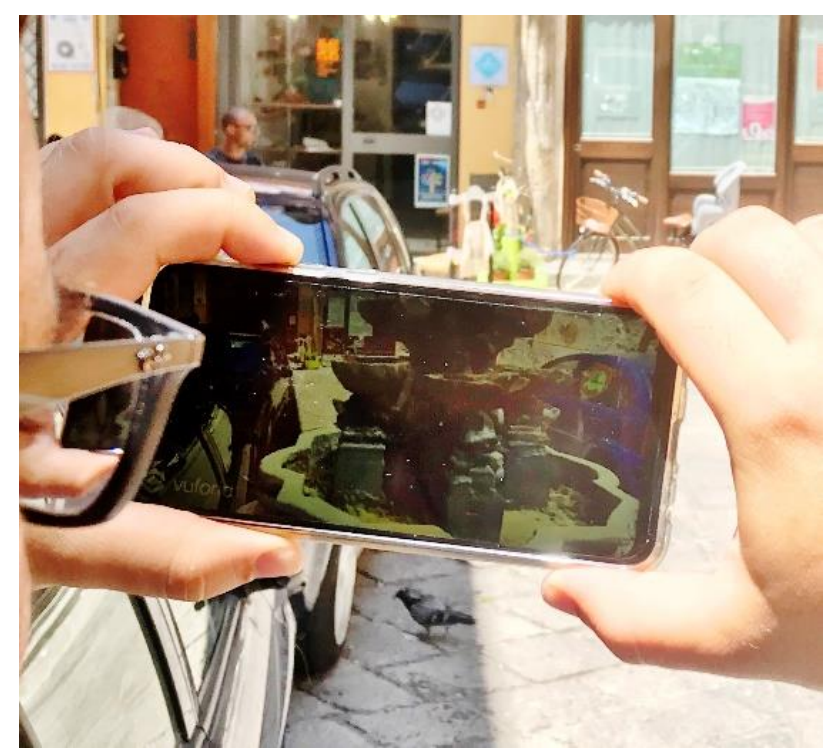

Figure 12. The testing of the outdoor AR experimentation: the 3D virtual model of the Garraffo fountain appears in the real environment of Piazza Garraffo, in correspondence with its original location.

Finally, the 3D printed model of the fountain, used as a 3D target for the AR application, can be also exploited as a tactile model for blind people. Museums and archeological sites can use these models for virtual and physical application, improving the experience of every kind of user. The scenarios and the possibilities opened from this application are a lot, because destroyed parts of $\mathrm{CH}$ find and monuments can therefore come back to life and enchant the visitor.

So, it's possible to say that this experimentation belongs to an idea of accessibility to $\mathrm{CH}$ the goes beyond the concept of architectural barriers, giving the possibility to time travel and discover in real time past configurations of historical environments.

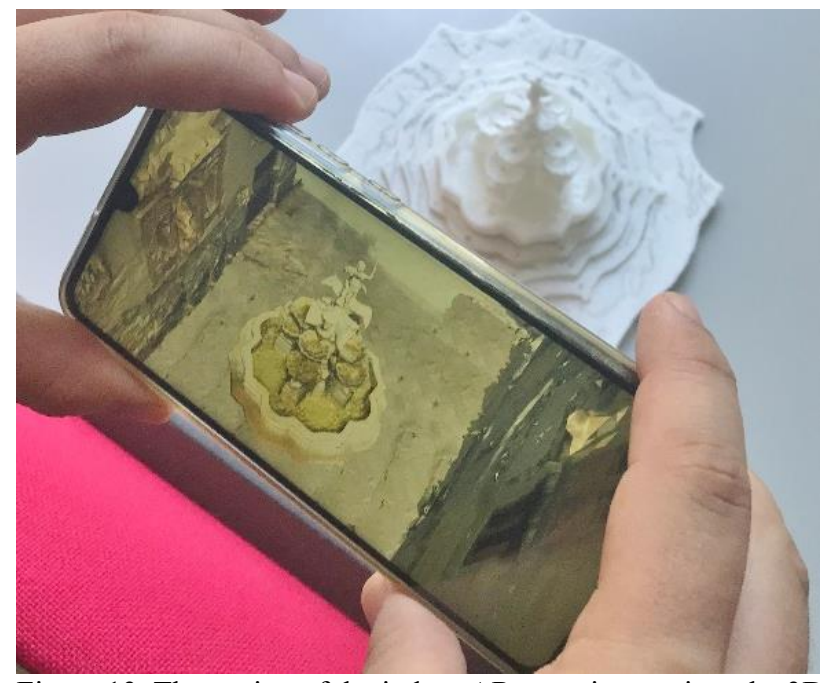

Figure 13. The testing of the indoor AR experimentation: the 3D virtual model of the Garraffo fountain inside its original location appears in correspondence of the 3D printed model.

\section{FUNDING}

This research was funded by Interreg I-ACCESS project "Implementing the Accessibility to Urban Historic Center's Use and Knowledge”, project code C1-1.1-41 - Axis 1. 


\section{REFERENCES}

Balletti, C., Berto, M., Gottardi, C., Guerra, F., 2014. 3D Technologies for the Digital Documentation of an Ancient Wooden Structure. International Journal of Heritage in the Digital Era, 3(1), 19-32.

Bekele, M. K., Pierdicca, R., Frontoni, E., Malinverni, E. S., Gain, J., 2018. A Survey of Augmented, Virtual, and Mixed Reality for Cultural Heritage. ACM Journal on Computing and Cultural Heritage, 11(2).

Carmigniani, J., Furht, B., Anisetti, M., Ceravolo, P., Damiani, E., Ivkovic, M., 2011. Augmented reality technologies, systems and applications. Multimedia tools and applications, 51(1), 341377.

D'Agnano, F., Balletti, C., Guerra, F., Vernier, P., 2015. Tooteko: A case study of augmented reality for an accessible cultural heritage. Digitization, 3D printing and sensors for an audiotactile experience. The International Archives of Photogrammetry, Remote Sensing and Spatial Information Sciences, 40(5), 207.

Damala, A., Stojanovic, N., Schuchert, T., Moragues, J., Cabrera, A., Gilleade, K., 2012. Adaptive Augmented Reality for Cultural Heritage: ARtSENSE Project. Euro-Mediterranean Conference (p. 746-755). Berlin, Heidelberg: Springer.

Dominici, D., Alicandro, M., Massimi, V., 2017. UAV photogrammetry in the post-earthquake scenario: case studies in L'Aquila. Geomatics, Natural Hazards and Risk, 8(1), 87-103.

Galatis, P., Gavalas, D., Kasapakis, V., Pantziou, G., Zaroliagis, C., 2016. Mobile Augmented Reality Guides in Cultural Heritage. MobiCASE, 11-19.

Hernández, L. A., Taibo, J., Blanco, D., Iglesias, J. A., Seoane, A., Jaspe, A., López, R., 2007. A Virtual Reality Installation for Exploration of Historical Heritage. International journal of architectural computing, 5(3), 487-506.

Lingua, A., Noardo, F., Spanò, A., Sanna, S., Matrone, F., 2017. 3D Model Generation Using Oblique Images Acquired By UAV. International Archives of the Photogrammetry, Remote Sensing \& Spatial Information Sciences, 42, 107-115.

Invitto, S., Spada, I., Turco, D., Belmonte, G., 2014. Easy Perception Lab: Evolution, Brain and Virtual and Augmented Reality in Museum Environment. International Conference on Augmented and Virtual Reality (p. 302-310). Cham: Springer.

Ioannides, M., Chatzigrigoriou, P., Bokolas, V., Nikolakopoulou, V., Athanasiou, V., Papageorgiou, E., Leventis, G., Sovis, C., 2016. Educational Creative Use and Reuse of Digital Cultural Heritage Data for Cypriot UNESCO Monuments. In: Ioannides M. et al. (eds) Digital Heritage. Progress in Cultural Heritage: Documentation, Preservation, and Protection. EuroMed 2016. Lecture Notes in Computer Science, vol 10058. Springer, Cham

Kim, K., Seo, B.-K., Han, J.-H., Park, J.-I., 2009. Augmented reality tour system for immersive experience of cultural heritage. Proceedings of the 8th International Conference on Virtual Reality Continuum and its Applications in Industry, (p. 323-324). Yokohama, Japan.
Liarokapis, F., 2007. An augmented reality interface for visualizing and interacting with virtual content. Virtual Reality, 11(1), 23-43.

Mangiameli, M., Mussumeci, G., Zito, S., 2017. Low cost digital photogrammetry: From the extraction of point clouds by SFM technique to $3 \mathrm{D}$ mathematical modeling. AIP Conference Proceedings. Vol. 1863. No. 1. AIP Publishing, 2017.

Marques, L., Tenedório, J. A., Burns, M., Româo, T., Birra, F., Marques, J., Pires, A., 2017. Cultural Heritage 3D Modelling and visualisation within an Augmented Reality Environment, based on Geographic Information Technologies and mobile platforms. Architecture, City and Environment, 11(33), 117-136.

Masiero, A., Fissore, F., Guarnieri, A., Piragnolo, M., Vettore, A., 2017. Comparison of low cost photogrammetric survey with TLS and Leica pegasus backpack $3 \mathrm{~d}$ modelss. The International Archives of Photogrammetry, Remote Sensing and Spatial Information Sciences, 42, 147.

Pepe, M., Fregolese, L., 2019. Application Of The Sfm Approach In Building 3D Models Of Masonry Bridges Using Nadir, Oblique And Zenith Images Obtained From UAV Aerial Platform. International Journal of Civil Engineering and Technology 10(04), 471-483.

Piras, M., Di Pietra, V., Visintini, D., 2017. 3D modeling of industrial heritage building using COTSs system: Test, limits and performances. The International Archives of Photogrammetry, Remote Sensing and Spatial Information Sciences, 42, 281.

Remondino, F., Barazzetti, L., Nex, F., Scaioni, M., Sarazzi, D., 2011. UAV photogrammetry for mapping and 3d modelingcurrent status and future perspectives. International archives of the photogrammetry, remote sensing and spatial information sciences 38.1 (2011): C22.

Scianna, A., La Guardia, M., 2018. 3D Virtual CH Interactive Information Systems for a smart web browsing experience for desktop PCs and mobile devices. International Archives of the Photogrammetry, Remote Sensing \& Spatial Information Sciences, 42(2).

Vacca, G., Dessì, A., Sacco, A., 2017. The Use of Nadir and Oblique UAV Images for Building Knowledge. ISPRS Int. J. Geo-Inf. 2017, 6, 393.

Vlahakis, V., Karigiannis, J., Tsotros, M., Gounaris, M., Almeida, L., Stricker, D., Ioannidis, N., 2002. ARCHEOGUIDE: First results of an Augmented Reality, Mobile Computing System in Cultural Heritage Sites. EEE Computer Graphics and Applications, 22(5), 52-60.

Wojciechowski, R., Walczak, K., White, M., \& Cellary, W., 2004. Building virtual and augmented reality museum exhibitions. Proceedings of the ninth international conference on $3 D \mathrm{Web}$ technology, 135-144. ACM.

Zöllner, M., Keil, J., Wüst, H., \& Pletinckx, D. (2009). An Augmented Reality Presentation System for Remote Cultural Heritage Sites. Proceedings of the 10th International Symposium on Virtual Reality, Archaeology and Cultural Heritage VAST, (p. 112-116). 